\title{
Introgression of a Novel Ug99-Effective Stem Rust Resistance Gene into Wheat and Development of Dasypyrum villosum Chromosome-Specific Markers via Genotyping-by-Sequencing (GBS)
}

\author{
Kaori Ando, ${ }^{1}$ Vandhana Krishnan, ${ }^{1}$ Sheri Rynearson, ${ }^{1}$ Matthew N. Rouse, ${ }^{2}$ Tatiana Danilova, ${ }^{3}$ Bernd Friebe, ${ }^{3}$ Deven See, ${ }^{4}$ \\ and Michael O. Pumphrey ${ }^{1, \dagger}$ \\ ${ }^{1}$ Department of Crop and Soil Sciences, Washington State University, Pullman, WA 99164 \\ ${ }^{2}$ United States Department of Agriculture-Agricultural Research Service (USDA-ARS), Cereal Disease Laboratory and Depart- \\ ment of Plant Pathology, University of Minnesota, St. Paul, MN 55108 \\ ${ }^{3}$ Wheat Genetics Resource Center, Kansas State University, Manhattan, KS 66506 \\ ${ }^{4}$ USDA-ARS, Western Regional Small Grains Genotyping Laboratory and Department of Plant Pathology, Washington State \\ University, Pullman, WA 99164
}

\begin{abstract}
Dasypyrum villosum is a wild relative of common wheat (Triticum aestivum L.) with resistance to Puccinia graminis f. tritici, the causal agent of stem rust, including the highly virulent race TTKSK (Ug99). In order to transfer resistance, $T$. durum-D. villosum amphiploids were initially developed and used as a bridge to create wheat $-D$. villosum introgression lines. Conserved ortholog set (COS) markers were used to identify $D$. villosum chromosome introgression lines, which were then subjected to seedling $P$. graminis f. tritici resistance screening with race TTKSK. A COS marker-verified line carrying chromosome $2 \mathrm{~V}$ with

line MS2V(2D) $\left(20^{\prime \prime}+1^{\prime} 2 \mathrm{~V}[2 \mathrm{D}]\right)$. This is the first report of stem rust resistance on $2 \mathrm{~V}$, which was temporarily designated as SrTA10276-2V. To facilitate the use of this gene in wheat improvement, a complete set of previously developed wheat $-D$. villosum disomic addition lines was subjected to genotyping-by-sequencing analysis to develop $D$. villosum chromosome-specific markers. On average, 350 markers per chromosome were identified. These markers can be used to develop diagnostic markers for $D$. villosum-derived genes of interest in wheat improvement.
\end{abstract} TTKSK resistance was further characterized by combined genomic in situ and fluorescent in situ analyses to confirm a monosomic substitution
Keywords: cereals and grains, field crops, fungi, techniques.
Dasypyrum villosum (L.) P. Candargy $(2 \mathrm{n}=2 \mathrm{x}=14$, VV) is an outcrossing tertiary gene pool relative of wheat (Triticum aestivum L.). The species originated around the northeastern Mediterranean and Caucasus region (De Pace et al. 2011) and has been utilized for wheat improvement due to abiotic stress tolerance, including salt and drought, as well as resistance to several wheat diseases, including

Current address of K. Ando: USDA-ARS, Crop Improvement and Protection Research Unit, Salinas, CA 93905.

Current address of V. Krishnan: Stanford Center for Genomics and Personalized Medicine, Department of Genetics, Stanford University, School of Medicine, Palo Alto, CA, 94305.

${ }^{\dagger}$ Corresponding author: M. O. Pumphrey; E-mail: m.pumphrey@wsu.edu

Funding: This project was supported by the College of Agriculture and Life Sciences, Cornell University as part of the Durable Rust Resistance in Wheat project, which was funded by the Bill and Melinda Gates Foundation and the United Kingdom Department for International Development.

*The $\boldsymbol{e}$-Xtra logo stands for "electronic extra" and indicates that one supplementary table, one supplementary file, and two supplementary figures are published online.

The author(s) declare no conflict of interest.

Accepted for publication 11 February 2019.

This article is in the public domain and not copyrightable. It may be freely reprinted with customary crediting of the source. The American Phytopathological Society, 2019 powdery mildew, eyespot, loose smuts, take-all disease, leaf spot, wheat curl mite, Wheat spindle streak mosaic virus, leaf rust, and stem rust (De Pace et al. 2011; Grądzielewska 2006). A collection of D. villosum accessions $(n=95)$ was previously screened, which revealed near-immunity of this species to wheat stem rust, caused by Puccinia graminis f. tritici Erikss. \& Hennings (Pumphrey et al. 2008).

Stem rust has reemerged as a threat to world wheat production since the emergence of a new virulent race, TTKSK (also known as Ug99), and evolution of related races (Singh et al. 2011, 2015). Stem rust has been effectively controlled by using resistance genes throughout the world in recent decades; however, the Ug99 race group defeated many effective wheat stem rust resistance $(\mathrm{Sr})$ genes and continues to evolve (Jin et al. 2008, 2009; Newcomb et al. 2016). The Ug99 race group is virulent to the majority of genes of common wheat origin. There are at least $41 \mathrm{Sr}$ genes effective against the Ug99 race group to date (Hiebert et al. 2016; Rahmatov et al. 2016; Singh et al. 2015). Thirteen genes are derived from common wheat backgrounds and the remaining are derived from other species belonging to the primary, secondary, and tertiary gene pools. One of the resistance genes, Sr52, was identified on D. villosum chromosome 6VL via a Robertsonian translocation (T6AS·6V\#3L) conferring resistance to TTKSK (Qi et al. 2011). Sr52 is the only $S r$ gene derived from $D$. villosum. It is important to broaden the genetic basis of stem rust resistance genes by acquiring new resistance genes from other gene pools, not only to control the disease but also to prolong the durability of the genes by pyramiding (McDonald and Linde 2002).

Alien gene transfer for disease resistance control in wheat is not a new concept. In order to transfer resistance genes from $D$. villosum to wheat, addition, substitution, and translocation lines were developed (Grądzielewska 2006). Creating these lines required specialized techniques, including embryo rescue and chromosome 
doubling techniques. To minimize the size of the transferred chromosome segments to reduce the potential for linkage to undesirable alleles on the same segments, inducing homologous recombination of chromosomes harboring resistance genes and developing chromosome-specific single-nucleotide polymorphism (SNP) markers spanning target chromosomes will help track alien resistance in a wheat background. Also, it provides markers for targeted chromosome engineering.

D. villosum is highly heterogeneous due to open pollination; therefore, it is challenging to develop adequate markers (De Pace et al. 2011; Qi et al. 2011). However, with the advances in molecular techniques, additional chromosome-specific markers were developed for genotyping (Cao et al. 2009; He et al. 2013; Liu et al. 2011; Qi et al. 2011; Zhang et al. 2006; R. Zhang et al. 2017; X. Zhang et al. 2017). Conserved ortholog set (COS) markers are developed based on genes which are highly conserved and low copy across a species and are suitable for comparisons to closely related species (Molnár et al. 2013; Pont et al. 2013; Quraishi et al. 2009). In total, 695 COS markers were developed based on rice-wheat orthologs and these markers are available for cereal genome research (Quraishi et al. 2009).

Genotyping-by-sequencing (GBS) is a recent high-throughput method of genotyping species with no reference genomes (Poland and Rife 2012; Poland et al. 2012). GBS reduces the genome information by using restriction enzymes targeting intron and exon regions to capture the polymorphic regions. This approach is especially suitable for species such as $D$. villosum with limited sequence information, because it can provide de novo sequence and marker information simultaneously.

In this study, we created T. durum-D. villosum amphiploids from four $D$. villosum accessions. These amphiploids were screened with TTKSK and the resistant lines were advanced to develop wheat$D$. villosum single-chromosome introgression lines. A wheat $-D$. villosum monosomic substitution line containing $D$. villosum chromosome $2 \mathrm{~V}$ conferred TTKSK resistance. To facilitate the transfer of this new stem rust resistance gene to wheat, GBS was used to genotype a complete set of Chinese Spring (CS)-D. villosum addition lines to anchor $D$. villosum sequence tags on each chromosome.

\section{Materials and Methods}

Plant material. D. villosum accessions and a complete chromosome series of wheat $-D$. villosum disomic additions DA1V\#3
(TA7677) through DA7V\#3 (TA7683) and a set of Robertsonian translocations (cRobTs) involving 12 of the 14 D. villosum chromosomes were obtained from the Kansas State University Wheat Genetic Resource Center (Table 1). Tetraploid T. durum 'Rusty' (PI 639869) (Klindworth et al. 2006), susceptible to all $P$. graminis f. tritici races tested in North America and races of exotic origin, was used as the female in crosses with $D$. villosum to make amphiploids. A population of $\mathrm{F}_{2: 3}$ families of amphiploids Rusty/TA10276B//Rusty// TA2126B (Table 2) were created for allelism testing. CS was used for subsequent crosses with amphiploids to produce wheat $-D$. villosum single-chromosome introgression lines. Initially, the amphiploids were used as female plants and CS was used as the pollen donor to produce $\mathrm{F}_{1}$ seed. These $\mathrm{F}_{1}$ plants were backcrossed to $\mathrm{CS}$ as female to create $\mathrm{BC}_{1} \mathrm{~F}_{1}$ progeny. The $\mathrm{BC}_{1} \mathrm{~F}_{1}$ progeny were further backcrossed to $\mathrm{CS}$ or self-pollinated until representative single $D$. villosum introgression lines were isolated. D. villosum accession TA10260 was used for DNA extraction to produce a $D$. villosumspecific genomic in situ hybridization (GISH) probe; and TA5617, a 6AS-6VL translocation line, was used as a GISH-positive control.

Embryo rescue and colchicine treatment. Immature embryos of Rusty/D. villosum hybridizations were removed from the spikes 14 days after pollination. Immature embryos were sterilized with $20 \%$ commercial bleach solution (containing 6\% $\mathrm{NaOCl}$ ) for $20 \mathrm{~min}$ followed by rinsing with sterilized water three times in a laminar hood. Immature embryos were isolated under a dissecting scope. The embryos were placed on wheat embryo rescue (ER) medium containing Murashige and Skoog (MS) basal salt mixture

Table 2. Parental and Rusty-Dasypyrum villosum amphiploid infection types in response to Puccinia graminis race TTKSK at seedling stage

\begin{tabular}{llccc}
\hline & & \multicolumn{3}{c}{ Infection type $^{\mathbf{a}}$} \\
\cline { 3 - 5 } D. villosum accessions & Origin & Parent & A & B \\
\hline TA2126 & Croatia & $0 ;$ & $13-$ & $0 ;$ \\
TA2197 & Bosnia & $0 ;$ & $0 ;$ & $0 ;$ \\
TA10260 & Greece & $0 ;$ & $0 ; 1$ & - \\
TA10276 & Greece & $0 ;$ & $3+$ & 2 \\
\hline
\end{tabular}

${ }^{a} \mathrm{~A}$ and $\mathrm{B}$ represent different primary amphiploid plants. Seedling infection types were scored based on a 0-to-4 scale by (Stackman et al. 1962).

Table 1. List of genotypes used for this study

\begin{tabular}{|c|c|c|c|}
\hline Genotype & Genetic stocks & Description $^{\mathbf{a}}$ & Reference \\
\hline TA2197 & Dasypyrum villosum & D. villosum & $\ldots$ \\
\hline TA2126 & D. villosum & D. villosum & $\ldots$ \\
\hline TA10276 & D. villosum & D. villosum & $\ldots$ \\
\hline TA10260 & D. villosum & D. villosum & $\ldots$ \\
\hline TA7677 & DA1V & $\mathrm{CS}-D$. villosum disomic addition $1 \mathrm{~V} \# 3$ & Lukaszewski, unpublished \\
\hline TA7678 & $\mathrm{DA} 2 \mathrm{~V}$ & $\mathrm{CS}-D$. villosum disomic addition $2 \mathrm{~V} \# 3$ & $\ldots$ \\
\hline TA7679 & $\mathrm{DA} 3 \mathrm{~V}$ & CS-D. villosum disomic addition $3 \mathrm{~V} \# 3$ & $\ldots$ \\
\hline TA7680 & $\mathrm{DA} 4 \mathrm{~V}$ & CS-D. villosum disomic addition $4 \mathrm{~V} \# 3$ & $\ldots$ \\
\hline TA7681 & DA5V & CS-D. villosum disomic addition $5 \mathrm{~V} \# 3$ & $\ldots$ \\
\hline TA7682 & DA6V & $\mathrm{CS}-D$. villosum disomic addition $6 \mathrm{~V} \# 3$ & $\ldots$ \\
\hline TA7683 & DA7V & CS-D. villosum disomic addition 7V\#3 & $\ldots$ \\
\hline TA5616 & $\mathrm{T} 1 \mathrm{DL} \cdot 1 \mathrm{~V} \# 3 \mathrm{~S}$ & cRobT CS-D. villosum 1DL/1VS & Liu et al. (2011) \\
\hline TA5615 & T1DS·1V\#3L & cRobT CS-D. villosum $1 \mathrm{DS} / 1 \mathrm{VL}$ & $\ldots$ \\
\hline TA5634 & $\mathrm{T} 2 \mathrm{BS} \cdot 2 \mathrm{~V} \# 3 \mathrm{~L}$ & cRobT CS-D. villosum 2BS/2VL & $\ldots$ \\
\hline TA5636 & $\mathrm{T} 3 \mathrm{DL} \cdot 3 \mathrm{~V} \# 3 \mathrm{~S}$ & cRobT CS-D. villosum 3DL/3VS & $\ldots$ \\
\hline TA5637 & T3DS $\cdot 3 \mathrm{~V} \# 3 \mathrm{~L}$ & cRobT CS-D. villosum 3DS/3VL & $\ldots$ \\
\hline TA5595 & $\mathrm{T} 4 \mathrm{DL} \cdot 4 \mathrm{~V} \# 3 \mathrm{~S}$ & cRobT CS-D. villosum 4DL/4VS & $\ldots$ \\
\hline TA5594 & T4DS·4V\#3L & cRobT CS-D. villosum 4DS/4VS & $\ldots$ \\
\hline TA5638 & T5DL·5V\#3S & cRobT CS-D. villosum 5DL/5VS & $\ldots$ \\
\hline TA5618 & $\mathrm{T} 6 \mathrm{AL} \cdot 6 \mathrm{~V} \# 3 \mathrm{~S}$ & cRobT CS-D. villosum 6AL/6VS & $\ldots$ \\
\hline TA5617 & T6AS $6 \mathrm{~V} \# 3 \mathrm{~L}$ & cRobT CS-D. villosum 6AS/6VL & $\ldots$ \\
\hline TA5639 & $\mathrm{T} 7 \mathrm{DL} \cdot 7 \mathrm{~V} \# 3 \mathrm{~S}$ & cRobT CS-D. villosum 7DL/7VS & $\ldots$ \\
\hline TA5640 & T7DS·7V\#3L & cRobT CS-D. villosum 7DS/7VL & $\ldots$ \\
\hline Rusty (R) & PI 639869 & Triticum turgidum & Klindworth et al. (2006) \\
\hline $\mathrm{CS}$ & TA3803 & T. aestivum & $\ldots$ \\
\hline
\end{tabular}

${ }^{\mathrm{a}} \mathrm{CS}=$ Chinese Spring and $\mathrm{cRobT}=$ Robertsonian translocation. 
(PhytoTechnology Laboratory, Shawnee Mission, KS, U.S.A.), 1\% Gamborg B5 vitamins (PhytoTechnology Laboratory), 3\% sucrose (bioWORLD, Dublin, OH, U.S.A.), kinetin at $2 \mathrm{mg} \cdot$ liter $^{-1}$ (SigmaAldrich, St. Louis, MO, U.S.A.), 0.2\% 2-(N-morpolino)ethanesulfonic acid (MES; PhytoTechnology Laboratory), and 0.2\% Gelrite (PlantMedia, Dublin, OH, U.S.A.) with pH 5.7 adjusted by KOH (SigmaAldrich) in a growth room with a 16 -h photoperiod at $24^{\circ} \mathrm{C}$. After embryos were germinated and formed several roots on the ER medium, seedlings were subcultured to shoot elongating medium which contains MS basal salt mixture, $1 \%$ Gamborg B5 vitamins, 4\% maltose (PhytoTechnology Laboratory), $0.01 \%$ ascorbic acid (Sigma-Aldrich), 0.2\% MES, and 0.2\% Gelrite with pH 5.7 until several tillers were formed. Seedlings were removed from the medium and transplanted into pots with potting medium that was covered with clear plastic and allowed to gradually reduce humidity. Once four to five leaves were formed, roots were cut about $2.5 \mathrm{~cm}$ and rinsed with distilled water to remove the potting medium. Subsequently, these seedlings were treated with $0.1 \%$ colchicine (SigmaAldrich) with $2 \%$ dimethyl sulfoxide (Sigma-Aldrich) for $7 \mathrm{~h}$ with light, then rinsed with running water for $20 \mathrm{~h}$. Rinsed plants were placed in the beaker and roots of the rinsed plants were submerged in distilled water, refrigerated for 3 days with $16 \mathrm{~h}$ of light, and covered with plastic wrap to avoid desiccation. After plants recovered from the colchicine treatment, they were transplanted in the potting medium and grown in the greenhouse.

Stem rust screening. TTKSK screening was conducted at the United States Department of Agriculture-Agricultural Research Service (USDA-ARS) Cereal Disease Laboratory in St. Paul, MN. Seedlings ( 7 to 9 days old) were inoculated with $P$. graminis f. tritici race TTKSK (isolate 04KEN156/04) using the protocol described by Rouse et al. (2011). Briefly, 7-day-old seedlings were inoculated with $P$. graminis f. tritici urediniospores suspended in Soltrol 70 oil. After inoculation, plants were air dried to evaporate the oil for at least $30 \mathrm{~min}$. Subsequently, inoculated plants were placed in a dew chamber at $22^{\circ} \mathrm{C}$ in darkness with $100 \%$ humidity for $16 \mathrm{~h}$. After $16 \mathrm{~h}$, fluorescent and incandescent lights were illuminated inside the dew chamber for $4 \mathrm{~h}$ to promote $P$. graminis f. tritici penetration. Plants were removed from the dew chamber and slowly dried, then placed in a growth chamber at 22 and $18^{\circ} \mathrm{C}$ (day and night, respectively) with a 16-h photoperiod. At least 18 to 20 plants were tested from each line. Twenty North American resistance gene differential genetic stocks were included to confirm the $P$. graminis f. tritici race in each experiment. Fourteen days post inoculation, plants were scored for seedling infection types using the 0 -to-4 scale described by Stakman et al. (1962).

DNA extraction and genotyping. Genomic DNA was extracted from freeze-dried 10-day-old plants using a BioSprint 96 DNA plant kit (Qiagen, Valencia, CA, U.S.A.) according to the manufacturer's protocol. DNA quality and quantity were assessed by Nanodrop. DNA concentration was adjusted to $25 \mathrm{ng} / \mu \mathrm{l}$. COS markers developed by Quraishi et al. (2009) and D. villosum chromosome armspecific markers (He at al. 2013; X. Zhang et al. 2017) were modified with the addition of the M13 tail (5'-CACGACATTGTAAAAC GAC) on each forward primer. In each $12-\mu 1$ reaction, $25 \mathrm{ng}$ of template DNA, $1.2 \mu$ l of $10 \times$ NEB polymerase chain reaction (PCR) buffer with $15 \mathrm{mM}$ of $\mathrm{MgCl}_{2}$ (New England BioLabs Inc. [NEB], Ipswich, MA, U.S.A.), $1.2 \mu \mathrm{l}$ of $2 \mathrm{mM}$ dNTP (Promega Corp., Madison, WI, U.S.A.), $0.48 \mu$ l of $25 \mathrm{mM} \mathrm{MgCl}_{2}$ (NEB), $0.3 \mu \mathrm{l}$ of $10 \mu \mathrm{m}$ reverse primer, $0.06 \mu \mathrm{l}$ of $0.1 \mu \mathrm{M}$ reverse primer, $0.24 \mu \mathrm{l}$ of $10 \mu \mathrm{M}$ M13 primer labeled with one of four fluorescent dyes (FAM, VIC, NED, and PED), and $0.2 \mu l$ of Taq (NEB) were used. A touchdown PCR method was used as follows. Initial denaturing was at $94^{\circ} \mathrm{C}$ for $5 \mathrm{~min}$; 12 touchdown cycles were performed at $95^{\circ} \mathrm{C}$ for $45 \mathrm{~s}, 64^{\circ} \mathrm{C}$ for $30 \mathrm{~s}$, and $72^{\circ} \mathrm{C}$ for $1 \mathrm{~min}$ with $0.5^{\circ} \mathrm{C}$ decrease per cycle; followed by 35 amplification cycles at $95^{\circ} \mathrm{C}$ for $45 \mathrm{~s}, 58^{\circ} \mathrm{C}$ for $30 \mathrm{~s}$, and $72^{\circ} \mathrm{C}$ for $1 \mathrm{~min}$; and a final extension at $72^{\circ} \mathrm{C}$ for $10 \mathrm{~min}$. An ABI 3730x Genotyper (Thermo Fisher Scientific, Waltham, MA, U.S.A.) was used to process the PCR products. Allele calling was processed by GeneMarker V1.91.

GBS was performed at the USDA-ARS Western Regional Small Grains Genotyping Lab, Pullman WA, following the method described by Poland et al. (2012) and Truong et al. (2012). Genomic DNA was extracted as described previously. Quality and quantity of DNA was analyzed by a Synergy 2 microplate reader (Biotek, Winooski, VT, U.S.A.) using a fluorescent DNA quantitation kit (Bio-Rad, Hercules, CA, U.S.A.) and adjusted to $20 \mathrm{ng} / \mu \mathrm{l}$. Two restriction enzymes ( $P s t \mathrm{I}$ and $M s p \mathrm{I}$; NEB) were used and a unique barcode adaptor was ligated for multiplexing. After the libraries were pooled, a DNA fragment was selected with $2 \%$ size select e-gel and examined for size and molarity with Bioanalyzer (Agilent Technologies, Santa Clara, CA, U.S.A.) with the high sensitivity DNA kit. Chip P1v2 and Ion Proton IC 200 kits (Thermo Fisher Scientific) were used to process the libraries for Ion Proton System sequencing.

Selected D. villosum chromosome-specific GBS markers were verified by PCR. Primers were designed using Primer-BLAST (Ye et al. 2012). Parameters used for primer design were set to primer size between 15 to $25 \mathrm{bp}$, primer melting temperature between 57 and $63^{\circ} \mathrm{C}$, and maximum product size of $90 \mathrm{bp}$. In each $20-\mu \mathrm{l}$ reaction, $25 \mathrm{ng}$ of template DNA, $2 \mu \mathrm{l}$ of $10 \times$ PCR buffer (Qiagen), $4 \mu \mathrm{l}$ of $5 \times$ Q-solution (Qiagen), $2 \mu \mathrm{l}$ of $2 \mathrm{mM}$ dNTP (Promega Corp.), $0.5 \mu \mathrm{l}$ of $10 \mu \mathrm{m}$ primers, and $0.2 \mu \mathrm{l}$ of HotStart Taq DNA polymerase (Qiagen) were used. PCR conditions were as follows: after initial denaturing at $95^{\circ} \mathrm{C}$ for $15 \mathrm{~min}, 10$ touchdown cycles at $95^{\circ} \mathrm{C}$ for $30 \mathrm{~s}$, $65^{\circ} \mathrm{C}$ for $30 \mathrm{~s}$, and $72^{\circ} \mathrm{C}$ for $10 \mathrm{~s}$ with $0.5^{\circ} \mathrm{C}$ decrease per cycle;

Table 4. Infection type (IT) of Dasypyrum villosum single-chromosome introgression lines in response to Puccinia graminis race TTKSK at seedling stage

\begin{tabular}{llcc}
\hline & & \multicolumn{2}{c}{ Number of plants $^{\mathbf{a}}$} \\
\cline { 3 - 4 } Chromosome & Generation & IT;2- & IT3+ \\
\hline $1 \mathrm{~V}$ & $\mathrm{BC}_{3} \mathrm{~F}_{2}$ & $\ldots$ & 20 \\
$2 \mathrm{~V}$ & $\mathrm{BC}_{2} \mathrm{~F}_{2}$ & $10^{\mathrm{b}}$ & 10 \\
$3 \mathrm{~V}$ & $\mathrm{BC}_{4} \mathrm{~F}_{1}$ & $\ldots$ & 19 \\
$4 \mathrm{~V}$ & $\mathrm{BC}_{3} \mathrm{~F}_{2}$ & $\ldots$ & 20 \\
$5 \mathrm{~V}$ & $\mathrm{BC}_{3} \mathrm{~F}_{2}$ & $\ldots$ & 18 \\
$6 \mathrm{~V}$ & $\mathrm{BC}_{1} \mathrm{~F}_{2}$ & $\ldots$ & 20 \\
\hline
\end{tabular}

${ }^{a}$ Infection types at the seedling stage based on a 0-to-4 scale by Stakman et al. (1962).

${ }^{b}$ Number of plants tested had respective TTKSK phenotype.

Table 3. Primer sequences of Dasypyrum villosum chromosome specific conserved ortholog set (COS) markers

\begin{tabular}{llll}
\hline Marker $^{\mathbf{a}}$ & Chr. $^{\mathbf{b}}$ & \multicolumn{1}{c}{ Forward primer $^{\mathbf{c}}$} & \multicolumn{1}{c}{ Reverse primer } \\
\hline GPI:C: 749284 & $1 \mathrm{~V}$ & CTACGTGATTTTCTGGGTGG & TCGACACCTTCACTCTCTGG \\
GPI:C:753773 & $2 \mathrm{~V}$ & GGACAATGAGAAAGCAAAGG & CTTTGCAAGAGCATCAGAGG \\
GPI:C:757080 & 3V & AGTGCAAGTCTCTGTGGAGG & TCATTGAAACCAAGGACAGC \\
GPI:C:765452 & 4V & CCTCTTTCAGAAGGGAAAGC & GTACACCGCGTAGATGATCC \\
GPI:C:717465 & $5 \mathrm{~V}$ & TATATTGCTTGGACATTCTTTGG & GTTCACTAGCATGCCTTTCC \\
GPI:C: 749072 & 6V & GTCTTCACATTGATCCCAGC & TCTCAAGAACCTACCCTGCC \\
GPI:C:744741 & $7 \mathrm{~V}$ & CATTGACTCTAGACGGTGTCG & TATGGTTCCTTCAGCTTTGC \\
\hline
\end{tabular}

\footnotetext{
${ }^{\text {a }}$ Markers were developed by Quraishi et al. (2009).

${ }^{\mathrm{b}} D$. villosum chromosome.

${ }^{\mathrm{c}}$ M13 tail was added to forward primer.
} 
followed by 30 amplification cycles at $95^{\circ} \mathrm{C}$ for $30 \mathrm{~s}, 60^{\circ} \mathrm{C}$ for $30 \mathrm{~s}$, and $72^{\circ} \mathrm{C}$ for $10 \mathrm{~s}$; and a final extension at $72^{\circ} \mathrm{C}$ for $5 \mathrm{~min}$. The PCR products were separated in $2 \%$ agarose gels in Tris-borate-EDTA buffer and visualized by ethidium bromide staining under UV light.

Cytogenetic analysis. Initially, the presence of $D$. villosum chromatin in the TTKSK-resistant introgression lines was verified by GISH. Ten plants from each line were analyzed. The squash preparations and GISH procedure were performed according to Zhang et al. (2001), except that no T. aestivum blocking DNA was applied. To determine the homologous group of $D$. villosum chromosomes, multicolor fluorescence in situ hybridization (FISH) combined with GISH was used. Individual wheat chromosomes were identified by FISH staining of tandem repeats and D. villosum chromosomes were detected by GISH. Somatic chromosome preparations using the drop technique, direct probe labeling by nick translation, and the FISH procedure were performed according to Kato et al. (2006), with minor modifications, as previously described (Danilova et al. 2012). Genomic DNA was labeled with fluorescein-12-dUTP (catalog NEL413001EA; Perkin-Elmer, Waltham, MA); oligonucleotide probes Cy5-(GAA) 9 and TEX615-pAs1-2 (Danilova et al. 2012) were synthesized by Integrated DNA Technologies (Coralville, IA, U.S.A.). Chromosomes were counterstained with 4',6-diamidino-2-phenylindole (catalog number H-1200; Vector Laboratories, Burlingame, CA). Images were captured with a Zeiss Axioplan 2 microscope using camera CoolSNAP HQ2 (Photometrics,

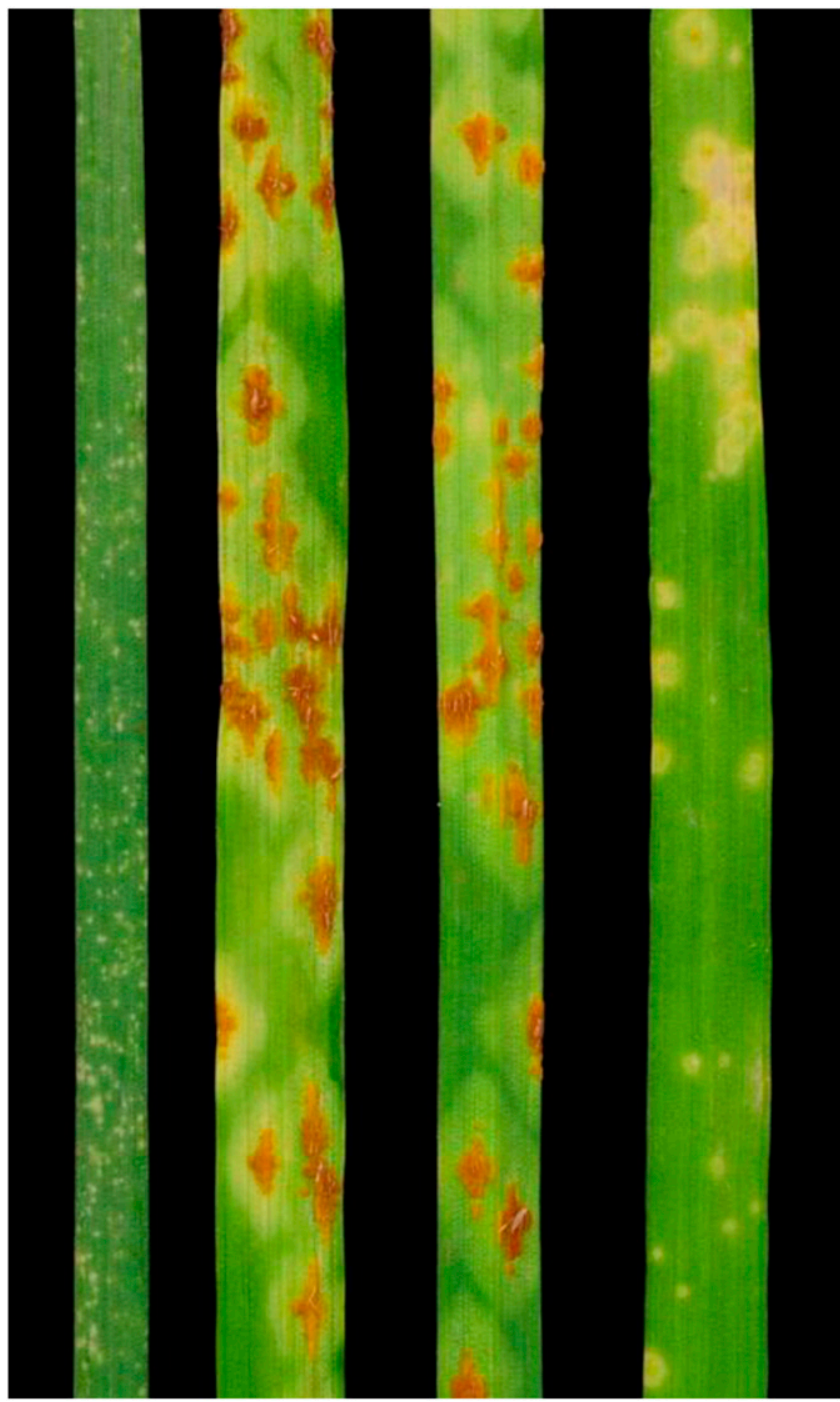

Fig. 1. Seedling reactions of parental lines and $10276-2 \mathrm{~V}$ to Puccinia graminis $\mathrm{f}$. tritici race TTKSK. Left to right: TA10276, Rusty, Chinese Spring, and 10276-2V.
Tucson, AZ U.S.A.) and AxioVision 4.8 software (Carl Zeiss AG, Oberkochen, Germany) and processed using the Adobe Photoshop software (Adobe Systems Incorporated, San Jose, CA, U.S.A.).

Bioinformatics analysis. The GBS tags that corresponded to Rusty and the CS reference sequence were assembled by combining five replicate sequencing runs from DNA extracted from distinct plants of each genotype. Similarly, sequences from four accessions of D. villosum (TA2126, TA2197, TA10260, and TA10276) were individually pooled from five individual plants representing each accession. The sequences that represented Rusty and CS were trimmed to a length of $100 \mathrm{bp}$ based on the mean sequence length for that run generated by the Ion Proton sequencing platform. The sequences for each $D$. villosum accession were also pooled and trimmed to $100 \mathrm{bp}$, and sequences with read depths of 4 to 9 were retained. The read depth cut-off is based on the trend of the frequency distribution of duplicated sequences. Similarly, each of the chromosomes from $D$. villosum additional lines (TA7677 to TA7683) was trimmed to a length of $100 \mathrm{bp}$ and only sequences that had a read depth of 3 or greater were retained. Then, the sequences for all the D. villosum chromosome addition lines were pooled. In each case, if sequences less than $100 \mathrm{bp}$ were detected posttrimming, these were excluded from downstream analysis.

From the pooled $D$. villosum addition line sequences, those with read depth greater than 1 were discarded, assuming that these were overrepresented by sequences in common with CS. Further, the remaining unique set of sequences in the $D$. villosum addition line pool were compared with the pooled CS sequences, and sequences that matched were discarded. This step ensured that sequences from CS that escaped the first filter on the D. villosum pool were removed. Next, sequences from the International Wheat Genome Sequencing Consortium (IWGSC) (The International Wheat Genome Sequencing Consortium 2014) that matched sequences in the CS filtered D. villosum pool were also discarded. To enable removal of IWGSC sequences, BLAST (Altschul et al. 1990; Madden 2002) was used, percentage identity was set to 100 , and those with alignment length of 100 were removed from the D. villosum pool. The common sequences between CS and IWGSC filter $D$. villosum additional line pool and $D$. villosum parent pool with read depth of 4 to 9 were identified using an in-house $\mathrm{R}$ script.

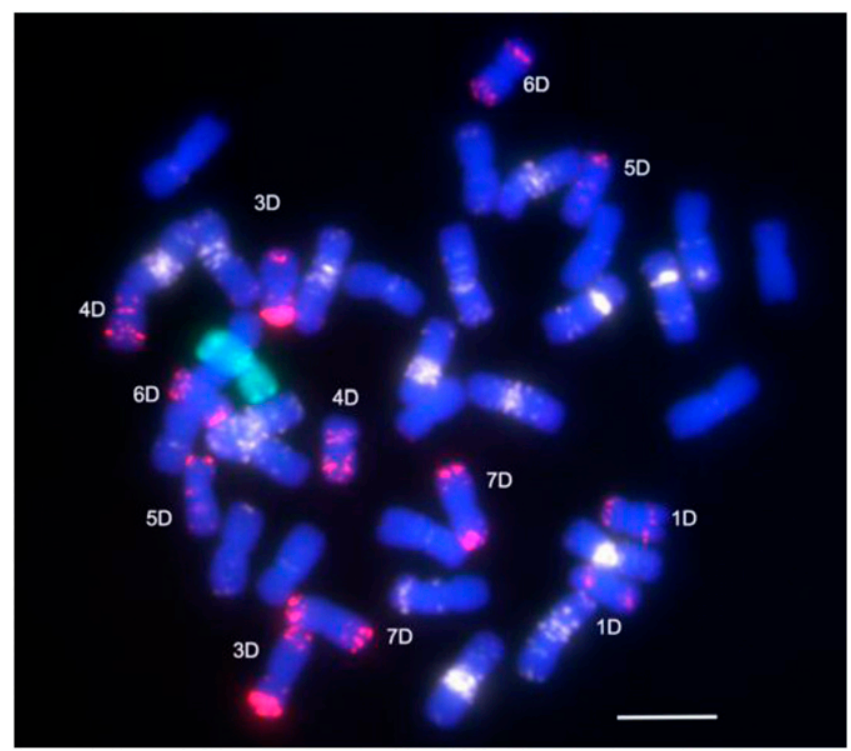

Fig. 2. Cytogenetic analysis of introgression line by combined genomic in situ hybridization (GISH) and fluorescence in situ hybridization (FISH). A monosomic substitution line MS2V(2D) $(2 n=41) 10276-2 V$ is shown. Wheat chromosomes were identified by patterns of tandem repeats pAs1 (red) and (GAA)n (white) Dasypyrum villosum chromatin was detected by GISH (green). Chromosomes were counterstained with 4',6-diamidino-2-phenylindole (blue). Bar corresponds to $10 \mu \mathrm{m}$. 


\section{Results}

Durum-D. villosum amphiploids for TTKSK screening. Four D. villosum accessions originating from the area surrounding the Mediterranean Sea were chosen to create durum-D. villosum amphiploids (Table 2). All four D. villosum accessions were highly resistant to infection against $P$. graminis f. tritici race TTKSK with 0 ; infection type (IT) (Supplementary Fig. S1). All of the amphiploids were also scored as resistant to TTKSK, with IT ratings ranging from 0 ; to 2, except one primary amphiploid of TA10276 with IT 3+. In cases where different primary amphiploids were tested from specific Rusty/D. villosum hybrids, responses to TTKSK infection were not always the same, indicating the heterogeneous nature of the D. villosum genome due to open pollination. Interestingly, in many cases, amphiploids were less resistant than $D$. villosum accessions. To examine the allelism of genes present among the accessions, an $\mathrm{F}_{2: 3}$ amphiploid population Rusty/TA10276B//Rusty/TA2126B was created. All 120 families were resistant to TTKSK with IT 0;. This could be due to the presence of multiple effective genes in both TA10276 and TA2126, or that their resistance is based on the same or tightly linked loci.

Identifying $D$. villosum single-chromosome introgression lines with COS markers and rust screening. Twenty-four COS markers were initially selected because they showed polymorphic patterns between the wheat $-D$. villosum DA lines and CS and Rusty. In all cases, CS and Rusty had the same peaks, whereas single DA lines had unique peaks. Finally, one COS marker per D. villosum chromosome was selected (Table 3). COS marker genotyping was repeated for each generation until a representative set of single $D$. villosum introgression lines was recovered. A set of single TA10276-D. villosum chromosome introgression lines at $\mathrm{BC}_{1} \mathrm{~F}_{2}$ to $\mathrm{BC}_{4} \mathrm{~F}_{1}$ generations was recovered, except for chromosome $7 \mathrm{~V}$ based on $\mathrm{COS}$ marker genotyping (Table 4). These lines were subjected to TTKSK screening and a line carrying $2 \mathrm{~V}$ based on COS genotyping was highly resistant to TTKSK (Fig. 1). Self-pollinated progeny of the $2 \mathrm{~V}$ introgression line showed a ;2 IT and the family was segregating for susceptibility. The $2 \mathrm{~V}$ line was named $10276-2 \mathrm{~V}$. The $S r$ gene in $10276-2 \mathrm{~V}$ was assigned temporary designation SrTA10276-2V. The remaining TA10276-D. villosum chromosome introgression lines were susceptible to TTKSK.

Cytogenetic analysis. The chromosome constitution of line 10276-2V was examined by a combined GISH and FISH method. We assumed that the missing wheat chromosomes were substituted by $D$. villosum homeologs. In 10 plants analyzed, chromosome numbers varied between 41 or $42 ; 1$ or 2 complete $D$. villosum chromosomes, sometimes in combination with short- or long-arm telosomes or isochromosomes, were present, all wheat A- and B-genome chromosomes were detected, and one or two 2D chromosomes were absent. The plant phenotype and fertility can confirm whether an alien chromosome is compensating for a wheat homologue (Dvořák 1980; Friebe et al. 1993; Sears 1952). The phenotype of line 10276-2V confirmed that the D. villosum chromosome was compensating for wheat $2 \mathrm{D}$. In addition, $D$. villosum chromosome arm-specific markers were used to verify the cytogenetic analysis. The line 10276-2V carried both long and short arms of $2 \mathrm{~V}$ and no other D. villosum chromosome arms (Supplementary Table S1).
The monosomic substitution line MS2V(2D), carrying a single D. villosum chromosome $2 \mathrm{~V}$ and missing wheat chromosome pair 2D with total chromosome number 41, is shown on Figure 2.

$D$. villosum-specific sequence marker development by GBS. In order to facilitate further introgression of the SrTA10276-2 V D. villosum resistance, chromosome-specific markers were developed via a GBS method. CS, Rusty, and wheat $-D$. villosum DA lines were sequenced and 177 million reads were generated from all of the samples with a mean read length of $159 \mathrm{bp}$. Initially, all seven wheatD. villosum DA line GBS reads were combined and compared with CS GBS reads and the IWGSC CS draft genome sequence to remove the perfect-match reads, resulting in 111,000 unique reads. Subsequently, the remaining GBS reads were compared with four accessions of $D$. villosum to verify the specificity of the reads. The majority of the GBS reads occurred in the D. villosum accessions fewer than two times. These reads were then compared with each of the seven disomic wheat- $D$. villosum addition line GBS reads. In total, 9,369 reads were assigned to each $D$. villosum chromosome, with read frequency ranging from 1 to 26 times and an average of 3.9 reads per marker. After filtering redundant reads, 2,444 reads were identified as specific to $D$. villosum chromosomes, ranging from 132 to 840 markers per chromosome, with an average of 349 (Table 5; Supplementary File S1). Selected markers were verified for their specificity to $D$. villosum chromosomes by PCR (Supplementary Fig. S2).

\section{Discussion}

New T. durum-D. villosum amphiploids with TTKSK resistance were created. These amphiploids exhibited a range of phenotypes in response to TTKSK infection, indicating that there may likely be several stem rust resistance genes present, which are yet to be characterized in $D$. villosum germplasm. In addition, $D$. villosum is an open-pollinating species; therefore, the genomes are highly heterogeneous. In fact, when different primary amphiploids from the same $D$. villosum accession were inoculated with TTKSK, different disease responses were frequently observed. The only other $\mathrm{Sr}$ gene reported to have originated in D. villosum, $S r 52$ on a T6AS 6 V\#3L translocation, is temperature sensitive, conferring a 2-infection type to TTKSK, and it is most effective at $16^{\circ} \mathrm{C}$ (Qi et al. 2011). In the current study, SrTA10276-2V was present on chromosome $2 \mathrm{~V}$ and was derived from the $D$. villosum accession TA10276. Intercrossing of primary amphiploids of TA10276 and TA2126 showed no susceptibility, suggesting that these may carry the same gene. Alternative explanations are that they are tightly linked or several (4+) unlinked genes are segregating in the cross, assuming typical inheritance, and our population size was too small to recover susceptible progeny. The TTKSK infection type of SrTA10276-2V was ;2, which is distinct compared with the IT of $S r 52$ under the same conditions.

COS markers developed based on rice-wheat orthologs (Quraishi et al. 2009) were used to genotype the wheat-D. villosum introgression lines. These COS markers were polymorphic between CS, Rusty, and wheat $-D$. villosum chromosomes. In our study, a combined analysis of GISH and FISH verified the COS genotyping result. According to Liu et al. (2011), DNA marker data and the GISH results generally agree; however, DNA marker genotyping

Table 5. Summary of Dasypyrum villosum chromosome-specific genotyping-by-sequencing (GBS) reads

\begin{tabular}{lcccc}
\hline D. villosum chromosome & Total GBS reads & Total unique reads & Mean unique reads & Unique reads range \\
\hline 1V & 504 & 132 & 3.8 & $1-22$ \\
2V & 1,751 & 466 & 3.8 & $1-26$ \\
3V & 3,113 & 840 & 3.8 & $1-26$ \\
4V & 1,180 & 310 & 4.5 & $1-25$ \\
$5 \mathrm{~V}$ & 652 & 144 & 3.9 & $1-18$ \\
6V & 902 & 233 & 4.0 & $1-24$ \\
$7 \mathrm{~V}$ & 1,267 & 319 & $\ldots$ & $\ldots$ \\
Total & 9,369 & 2,444 & 3.9 & $\ldots$ \\
Overall mean & $1,338.4$ & 349.1 & & \\
\hline
\end{tabular}


may create false-positive results by detecting chromatin in the absence of GISH signals. More dense marker systems may aid in discriminating between experimental error and the unusual but documented presence of cryptic translocation events (Tiwari et al. 2014). In addition, D. villosum is highly heterogeneous because of open pollination and suffers from rapid inbreeding depression, and the transferability of polymorphic markers from one accession to another accession is low. To address this, we tested four accessions of D. villosum for COS markers which can be used for each accession. Using these COS markers, we were able to recover a majority of single $D$. villosum chromosome introgression lines for each accession (data not shown).

Approximately 2,500 D. villosum chromosome-specific markers were detected by GBS. By testing these markers on Robertsonian translocation lines created by Liu et al. (2011), the markers can be further assigned to chromosome arms. This will help to minimize the number of markers for screening of introgression or mapping populations and these markers may be useful for marker-assisted breeding as translocation stocks with small introgression events are developed. Moreover, current $D$. villosum sequence information is limited, and there are only a few markers for each chromosome. Therefore, this marker system should streamline working with this allele-rich alien species.

Four $D$. villosum accessions were genotyped by GBS to allow investigation of polymorphism between accessions. Filtered GBS sequences that were only common among these four accessions were assigned to chromosomes. In our current study, we developed presence or absence variation (PAV) markers that are specific to individual $D$. villosum chromosomes. However, the GBS raw dataset is dynamic and can be reanalyzed to uncover further information (Poland and Rife 2012). Therefore, the same raw dataset can be used as is and integrated with new data to develop SNP or PAV markers in future studies.

The 10276-2V line was determined to be a monosomic substitution line MS2V(2D) using cytogenetic analysis. It was missing a pair of $2 \mathrm{D}$ chromosomes and one $D$. villosum chromosome $2 \mathrm{~V}$. Chromosome $2 \mathrm{~V}$ from various $D$. villosum accessions has been previously associated with resistance to eyespot (caused by Oculimacula yallundae and $O$. acuformis), Wheat streak mosaic virus resistance, stripe rust (caused by $P$. striiformis f. tritici), and zinc accumulation (Chen et al. 2008; De Pace et al. 2011). The MS2V(2D) substitution line is the starting point for further directed chromosome engineering aimed at producing compensating wheat-2V recombinants with shortened $D$. villosum chromatin but still retaining the stem rust resistance gene.

\section{Acknowledgments}

We thank V. DeMacon, S. Rynearson, D. Rider, and J. Logan for their technical assistance; and S. Xu, U. Gill, and H. Trick for sharing experiment materials and protocols.

\section{Literature Cited}

Altschul, S. F., Gish, W., Miller, W., Myers, E. W., and Lipman, D. J. 1990. Basic local alignment search tool. J. Mol. Biol. 215:403-410.

Cao, Y.-P., Cao, A.-Z., Wang, X.-E., and Chen, P.-D. 2009. Screening and application of EST-based PCR markers specific to individual chromosomes of Haynaldia villosa. Acta Agron. Sin. 35:1-10.

Chen, Q., Cao, A., Qi, Z., Zhang, W., and Chen, P. 2008. Structural changes of 2V chromosome of Haynaldia villosa induced by gametocidal chromosome $3 \mathrm{C}$ of Aegilops triuncialis. Agric. Sci. China 7:804-811.

Danilova, T. V., Friebe, B., and Gill, B. S. 2012. Single-copy gene fluorescence in situ hybridization and genome analysis: Acc-2 loci mark evolutionary chromosomal rearrangements in wheat. Chromosoma 121:597-611.

De Pace, C., Vaccino, P., Cionini, P. G., Pasquini, M., Bizzarri, M., and Qualset, C. O. 2011. Dasypyrum. Pages 185-292 in: Wild Crop Relatives: Genomic and Breeding Resources: Cereals. C. Kole, ed. Springer Berlin Heidelberg, Berlin, Heidelberg, Germany.

Dvořák, J. 1980. Homoeology between Agropyron elongatum chromosomes and Triticum aestivum chromosomes. Can. J. Genet. Cytol. 22:237-259.

Friebe, B., Tuleen, N., Jiang, J. M., and Gill, B. S. 1993. Standard karyotype of Triticum longissimum and its cytogenetic relationship with T. aestivum. Genome 36:731-742.

Grądzielewska, A. 2006. The genus Dasypyrum-Part 2. Dasypyrum villosum-A wild species used in wheat improvement. Euphytica 152:441-454.
He, H., Zhu, S., Sun, W., Gao, D., and Bie, T. 2013. Efficient development of Haynaldia villosa chromosome 6VS-specific DNA markers using a CISP-IS strategy. Plant Breed. 132:290-294.

Hiebert, C. W., Kassa, M. T., McCartney, C. A., You, F. M., Rouse, M. N., Fobert, P., and Fetch, T. G. 2016. Genetics and mapping of seedling resistance to Ug99 stem rust in winter wheat cultivar Triumph 64 and differentiation of SrTmp, SrCad, and Sr42. Theor. Appl. Genet. 129:2171-2177.

Jin, Y., Szabo, L. J., Pretorius, Z. A., Singh, R. P., Ward, R., and Fetch, T. 2008. Detection of virulence to resistance gene $\mathrm{Sr} 24$ within race TTKS of Puccinia graminis f. sp. tritici. Plant Dis. 92:923-926.

Jin, Y., Szabo, L. J., Rouse, M. N., Fetch, T., Pretorius, Z. A., Wanyera, R., and Njau, P. 2009. Detection of virulence to resistance gene Sr36 within the TTKS race lineage of Puccinia graminis f. sp. tritici. Plant Dis. 93:367-370.

Kato, A., Kato, A., Albert, P., Vega, J., Kato, A., Albert, P., Vega, J. M., and Birchler, J. A. 2006. Sensitive fluorescence in situ hybridization signal detection in maize using directly labeled probes produced by high concentration DNA polymerase nick translation. Biotech. Histochem. 81:71-78.

Klindworth, D. L., Miller, J. D., and Xu, S. S. 2006. Registration of Rusty durum wheat. Crop Sci. 46:1012-1013.

Liu, C., Qi, L., Liu, W., Zhao, W., Wilson, J., Friebe, B., and Gill, B. S. 2011 Development of a set of compensating Triticum aestivum-Dasypyrum villosum Robertsonian translocation lines. Genome 54:836-844.

Madden, T. 2002. The BLAST sequence analysis tool. Chapter 16 in: The NCBI Handbook. J. McEntyre and J. Ostell, eds. National Center for Biotechnology Information, Bethesda, MD, U.S.A

McDonald, B. A., and Linde, C. 2002. Pathogen population genetics, evolutionary potential, and durable resistance. Annu. Rev. Phytopathol. 40:349-379.

Molnár, I., Šimková, H., Leverington-Waite, M., Goram, R., Cseh, A., Vrána, J., Farkas, A., Doležel, J., Molnár-Láng, M., and Griffiths, S. 2013. Syntenic Relationships between the U and M Genomes of Aegilops, wheat and the model species Brachypodium and rice as revealed by COS markers. PLOS ONE. 8:e70844.

Newcomb, M., Olivera, P. D., Rouse, M. N., Szabo, L. J., Johnson, J., Gale, S. Luster, D. G., Wanyera, R., Macharia, G., Bhavani, S., Hodson, D., Patpour, M., Hovmøller, M. S., Fetch, T. G., and Jin, Y. 2016. Kenyan isolates of Puccinia graminis f. sp. tritici from 2008 to 2014: Virulence to SrTmp in the Ug99 race group and implications for breeding programs. Phytopathology 106:729-736.

Poland, J. A., Brown, P. J., Sorrells, M. E., and Jannink, J. L. 2012. Development of high-density genetic maps for barley and wheat using a novel two-enzyme genotyping-by-sequencing approach. PLoS One 7:e32253.

Poland, J. A., and Rife, T. W. 2012. Genotyping-by-sequencing for plant breeding and genetics. Plant Genome 5:92-102.

Pont, C., Murat, F., Guizard, S., Flores, R., Foucrier, S., Bidet, Y., Quraishi, U. M., Alaux, M., Doležel, J., Fahima, T., Budak, H., Keller, B., Salvi, S., Maccaferri, M., Steinbach, D., Feuillet, C., Quesneville, H., and Salse, J. 2013. Wheat syntenome unveils new evidences of contrasted evolutionary plasticity between paleo- and neoduplicated subgenomes. Plant J. 76:1030-1044.

Pumphrey, M. O., Jin, Y., Rouse, M. N., Qi, L., Friebe, B., and Gill, B. S. 2008. Resistance to stem rust race TTKS in wheat relative Haynaldia villosa. In: Proc. 11th Int. Wheat Genet. Symp. Sydney, Australia. University Press.

Qi, L. L., Pumphrey, M. O., Friebe, B., Zhang, P., Qian, C., Bowden, R. L., Rouse, M. N., Jin, Y., and Gill, B. S. 2011. A novel Robertsonian translocation event leads to transfer of a stem rust resistance gene ( $S r 52)$ effective against race Ug99 from Dasypyrum villosum into bread wheat. Theor. Appl. Genet. 123:159-167.

Quraishi, U. M., Abrouk, M., Bolot, S., Pont, C., Throude, M., Guilhot, N., Confolent, C., Bortolini, F., Praud, S., Murigneux, A., Charmet, G., and Salse, J. 2009. Genomics in cereals: From genome-wide conserved orthologous set (COS) sequences to candidate genes for trait dissection. Funct. Integr. Genomics 9:473.

Rahmatov, M., Rouse, M. N., Nirmala, J., Danilova, T., Friebe, B., Steffenson, B. J., and Johansson, E. 2016. A new 2DS·2RL Robertsonian translocation transfers stem rust resistance gene Sr59 into wheat. Theor. Appl. Genet. 129:1383-1392.

Rouse, M. N., Wanyera, R., Njau, P., and Jin, Y. 2011. Sources of resistance to stem rust race Ug99 in spring wheat germplasm. Plant Dis. 95:762-766.

Sears, E. R. 1952. Homoeologous chromosomes in Triticum aestivum. Genetics 37:624

Singh, R. P., Hodson, D. P., Huerta-Espino, J., Jin, Y., Bhavani, S., Njau, P., Herrera-Foessel, S., Singh, P. K., Singh, S., and Govindan, V. 2011. The emergence of Ug99 races of the stem rust fungus is a threat to world wheat production. Annu. Rev. Phytopathol. 49:465-481.

Singh, R. P., Hodson, D. P., Jin, Y., Lagudah, E. S., Ayliffe, M. A., Bhavani, S., Rouse, M .N., Pretorius, Z. A., Szabo, L. J., Huerta-Espino, J., Baswnet, B. R. Lan, C., and Hovmøller, M. S. 2015. Emergence and spread of new races of wheat stem rust fungus: Continued threat to food security and prospects of genetic control. Phytopathology 105:872-884.

Stakman, E. C., Stewart, D. M., and Loegering, W. Q. 1962. Identification of physiologic races of Puccinia graminis var. tritici. United States Department of Agriculture-Agricultural Research Service E-617. https://www.ars.usda. gov/ARSUserFiles/50620500/Cerealrusts/Pgt/Stakman_code_Pgt.pdf

The International Wheat Genome Sequencing Consortium. 2014. A chromosomebased draft sequence of the hexaploid bread wheat (Triticum aestivum) genome. Science 345: Article 1251788. 
Tiwari, V. K., Wang, S., Sehgal, S., Vrána, J., Friebe, B., Kubaláková, M., Chhuneja, P., Doležel, J., Akhunov, E., Kalia, B., Sabir, J., and Gill, B. S. 2014. SNP discovery for mapping alien introgressions in wheat. BMC Genomics 15:273.

Truong, H. T., Ramos, A. M., Yalcin, F., de Ruiter, M., van der Poel, H. J. A., Huvenaars, K. H. J., Hogers, R. C. J., van Enckevort, L. J. G., Janssen, A., van Orsouw, N. J., and van Eijk, M. J. T. 2012. Sequence-based genotyping for marker discovery and codominant scoring in germplasm and populations. PLoS One 7:e37565.

Ye, J., Coulouris, G., Zaretskaya, I., Cutcutache, I., Rozen, S., and Madden, T. L. 2012. Primer-BLAST: A tool to design target-specific primers for polymerase chain reaction. BMC Bioinf. 13:134.

Zhang, P., Friebe, B., Lukaszewski, A. J., and Gill, B. S. 2001. The centromere structure in Robertsonian wheat-rye translocation chromosomes indicates that centric breakage-fusion can occur at different positions within the primary constriction. Chromosoma 110:335-344.

Zhang, R., Yao, R., Sun, D., Sun, B., Feng, Y., Zhang, W., and Zhang, M. 2017. Development of $\mathrm{V}$ chromosome alterations and physical mapping of molecular markers specific to Dasypyrum villosum. Mol. Breed. 37:67.

Zhang, W., Gao, A.-L., Zhou, B., and Chen, P.-D. 2006. Screening and applying wheat microsatellite markers to trace individual Haynaldia villosa chromosomes. Acta Genet. Sin. 33:236-243.

Zhang, X., Wei, X., Xiao, J., Yuan, C., Wu, Y., Cao, A., Xing, L., Chen, P., and Zhang, S. 2017. Whole genome development of intron targeting (IT) markers specific for Dasypyrum villosum chromosomes based on next-generation sequencing technology. Mol. Breed. 37:115. 